\title{
POLYGONAL TERRAINS ON MARS
}

\author{
JosÉ SARAIVA ${ }^{1}$ \\ LOURENÇO BANDEIRA ${ }^{1}$ \\ JOANA ANTUNES ${ }^{1}$ \\ PEDRO PINA ${ }^{1}$ \\ TERESA BARATA ${ }^{1}$
}

\begin{abstract}
The presence of water ice on Mars is well established. Some features on the planet point to the occurrence of processes similar to those that take place in periglacial areas of Earth. One of the clues for this is the existence of small-scale polygonal terrains. In this paper, we present a methodology that aims at the automated identification of polygonal patterns on high-spatial resolution images of the surface of Mars. In the context of the research project TERPOLI, this step will be complemented with a full characterization, in both geometric and topological terms, of the networks detected. In this manner, we hope to collect data that will lead to a better understanding of the conditions of formation of the polygons, and of their temporal evolution; namely, we intend to identify different groups of polygons and to compare them with terrestrial examples.
\end{abstract}

Keywords: Mars, polygonal terrains, detection, geometry, topology.

Resumo - Terrenos poligonais em Marte. A existência de água em Marte é um facto bem estabelecido. Na sua superfície existem exemplos de formas cuja origem pode estar relacionada com processos semelhantes aos que ocorrem em áreas periglaciárias da Terra. Uma das pistas para tal facto prende-se com a existência de terrenos poligonais. Neste artigo apresentamos uma metodologia cujo objectivo é a identificação automática de padrões poligonais em imagens de alta resolução espacial da superfície de Marte. No contexto do projecto TERPOLI, este estudo será complementado com uma caracterização das redes de polígonos detectadas, em termos geométricos e topológicos. Será assim recolhida informação que poderá levar a uma melhor compreensão das condições de formação e da evolução temporal dos polígonos. Entre os aspectos a trabalhar estão a definição de grupos de polígonos e a comparação com análogos terrestres.

Palavras-chave: Marte, terrenos poligonais, detecção, geometria, topologia.

Recebido: 07/12/2007. Revisto: 07/04/2009. Aceite: 14/05/2009.

1 CERENA/IST.E-mail: jose.saraiva@ist.utl.pt, lpc_bandeira@ist.utl.pt,jbantunes@ist.utl.pt, ppina@ist.utl.pt e mtbarata@gmail.com 
Résumé - Des terRains polygonauX sur MARs. La présence d'eau sur Mars est un fait avéré. Sa surface montre des exemples de formes, dont l'origine peut être rapportée à des processus analogues à ceux qu'on observe dans les espaces périglaciaires terrestres. Une des pistes d'étude peut être la présence de terrains polygonaux. On présente une méthodologie destinée à identifier automatiquement des réseaux polygonaux sur les images en haute résolution de la surface de Mars. Dans le contexte du projet TERPOLI, cette étude sera complétée par la caractérisation des réseaux polygonaux détectés, en termes géométriques et topologiques. Cette information permettra de mieux comprendre les conditions de formation et d'évolution temporelle des polygones, par la définition de groupes de polygones et par leur comparaison avec des types terrestres analogues.

Mots clés: Mars, terrains polygonaux, détection, géométrie, topologie.

\section{INTRODUCTION}

Mars is the fourth planet of the Solar System. Though it is generally considered the most Earth-like object in the system, it lies much farther from the Sun than our planet, and its orbital and physical characteristics all contribute to turn it into a global frozen desert. However, the existence of water on the planet is no longer an issue - there are vast quantities of water on Mars. In its atmosphere, there is a small proportion of water vapour; but by far the largest reservoir is in the polar caps, followed by the global cryolithosphere - that is, ice in the upper crust of the planet. Still, liquid water at its surface is, at best, viable in a few locations, where atmospheric pressure is higher (due to topographical depression) and temperature can reach into the twenties (centigrade). Some features, such as gullies carved into the interior walls of impact craters and valleys, seem to attest that water has flowed recently on the surface - but their very nature is far from being completely explained, and alternative mechanisms have been proposed for their origin. Liquid water on Mars, thus, has yet to be seen.

Some authors have considered the possible presence of $\mathrm{CO}_{2}$ ice in the global Martian permafrost, and this is an issue that still raises some discussion (Kuzmin, 2005). It must be stressed that the global cycles both of $\mathrm{H}_{2} \mathrm{O}$ and $\mathrm{CO}_{2}$ in the planet are far from being completely understood. There is a seasonal circulation of both components between the northern and southern polar caps, through the atmosphere; but its dynamics and its relation with the climatic evolution of Mars are yet to be fully illuminated. The planet has been the subject of a dedicated program of exploration. There are currently three active probes in orbit and two rovers still working on the surface. Another surface probe, the Phoenix Mars Lander, has reached a high latitude point in the northern hemisphere of Mars in May 2008 and completed its mission by November. Many scientific instruments have flown towards the planet onboard these probes, but only the cameras have given us detailed views of the morphology of the Martian surface. In the 1970s, the images collected by the Viking orbiters gave the first hints of the existence 
of polygons of large dimensions on Mars (Hiesinger and Head, 2000), while the landers pointed to the presence of networks of trenches in their vicinities. In the 1990 s, though, another NASA probe, Mars Global Surveyor, took high quality images of the whole surface of the planet. The camera onboard this satellite could work in a narrow-angle mode, taking images with a spatial resolution that came to 1.5 meters per pixel - and these images in particular have shown that polygonal terrains are not an unusual feature on the surface of Mars. In fact, their presence has been registered in a wide variety of settings, and not all of these occur in high-latitude areas; given the ubiquity of ice in the soil, though, there is a clear possibility of most being related to periglacial processes.

\section{PREVIOUS STUDIES AND THE PROJECT TERPOLI}

Polygonal terrains on Mars have been the subject of some studies, though their identification is still somewhat recent. Initial analysis were mostly concerned with qualitative approaches, concentrating namely on the distribution of polygons (Kossacki and Markiewicz, 2002; Kuzmin and Zabalueva, 2003; Mangold et al., 2004) and their visual aspect. One of the first quantified issues dealt with the distinction between polygons, based on their diameters; different authors have proposed diverse boundaries for classes of polygons (Yoshikawa, 2000; Langsdorf and Britt, 2005; Mangold, 2005), but these seem arbitrary, or rather strongly influenced by the number and kind of images analysed, with little or no statistical justification. The range of sizes has also been considered (Seibert and Kargel, 2001). Another basic issue that has been tackled is the morphometric characterization of polygons (Yoshikawa, 2000; Van Gasselt et al., 2005). This type of studies clearly points to the idea that polygons on Mars are comparable to those on the Earth, but little work has been done on the relations between the parameters of the networks and the conditions of formation of the polygons, namely about topographical and geological control. The temporal evolution of areas with abundant polygons has also been analysed (Van Gasselt et al, 2005), though studies of this kind are strongly limited by the availability of images of the same area with adequate time intervals. Finally, it must be said that all works mentioned are based on visual and manual identification of areas of interest, which is to say that they implied an intensive analysis of the images by a human operator.

Given that the results published so far on Mars polygonal terrains have been based on human analysis of images, and that the identification and characterization of natural networks can be achieved by automated procedures, whatever their nature (cell arrangement, patterns of fractures, etc.), we believe that the automation of analysis in this field can be a major contribution for the evolution of knowledge about polygonal terrains in planetary surfaces. That was the rationale behind the development of such a methodology, based on images of polygonal terrains on the surface of Mars, which led to the creation of project TERPOLI (Automatic Recognition and Characterization of Polygonal Terrains 
on Mars). In its execution, we have begun a thorough search for images of polygonal patterns on Mars. The stated objectives of this research project are the identification and characterization of polygonal networks, in order to contribute to the understanding of their formation and temporal evolution, taking into account what is known about analogue features on Earth.

According to data presented in previous studies, we elected to limit ourselves to latitudes (in both hemispheres) higher than $50^{\circ}$, and to concentrate on images acquired by the Mars Orbiter Camera (MOC) onboard the MGS probe, in its narrow-angle mode. In order to obtain data possessing some visual clarity, we further decided to establish an upper limit of 10 meters per pixel, that is, we only took into account the images for which spatial resolution is better than that. In figure 1, we present one of the resulting maps, showing the locations of 206 images of the northern hemisphere in which polygonal terrains are clearly seen. These were selected among 4280 high resolution MOC images. The search continues, now in the southern hemisphere, where polygonal terrains are much more common. In figure 2 we present some examples of the very diverse types and visual aspects of patterned ground that can be seen on images of the surface of Mars.

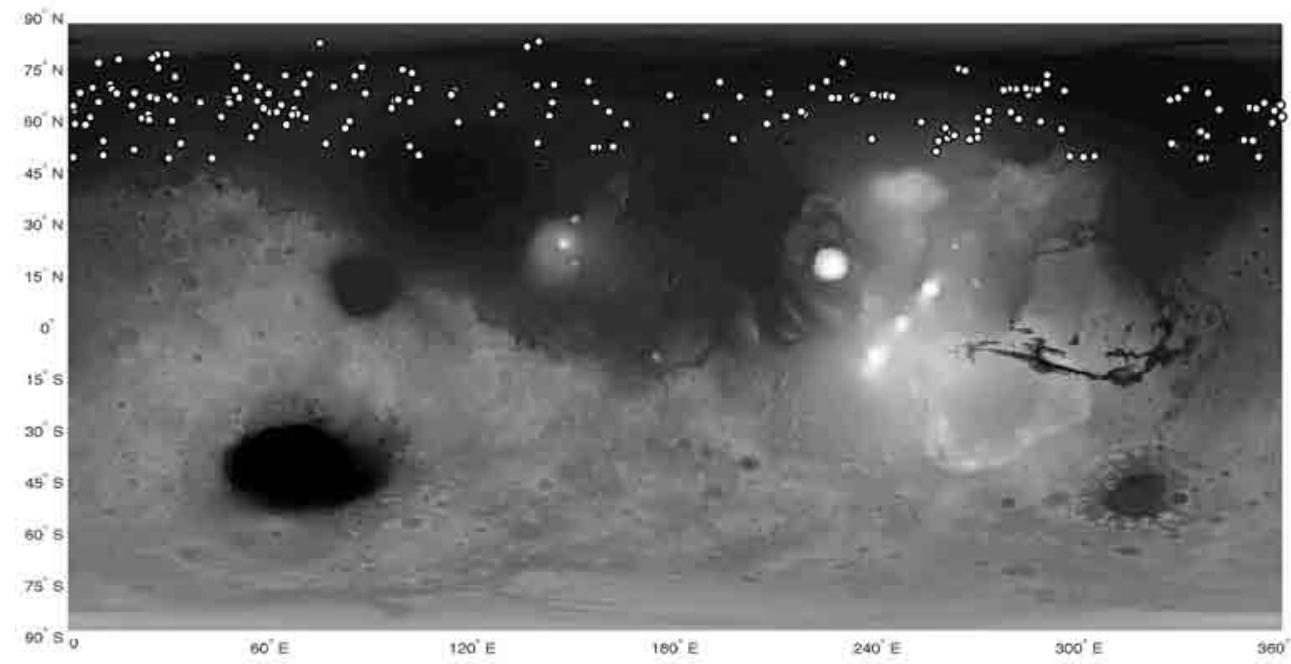

Fig. 1 - Location of MOC images containing polygonal terrains on the northern hemisphere of Mars (latitude higher than $50^{\circ}$ and spatial resolution better than $10 \mathrm{~m} / \mathrm{pixel}$ ).

Background is MOLA topography.

Fig. 1 - Localização das imagens MOC que contêm polígonos no hemisfério Norte de Marte (latitute superior a $50^{\circ}$ e resolução espacial superior a 10m/pixel). 


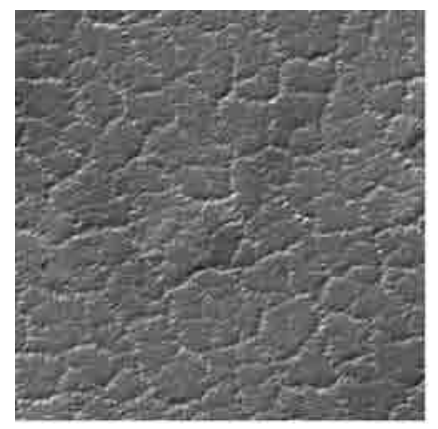

E0300299

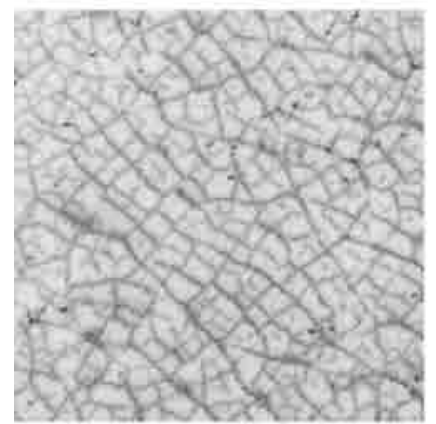

R0801628

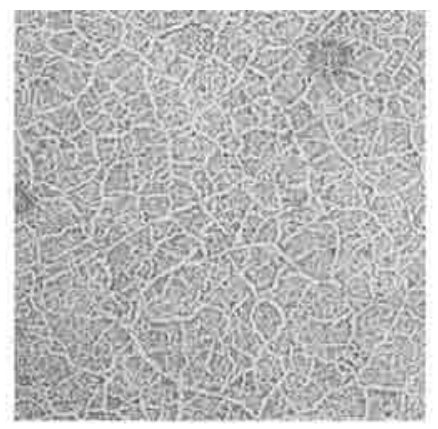

E0900029

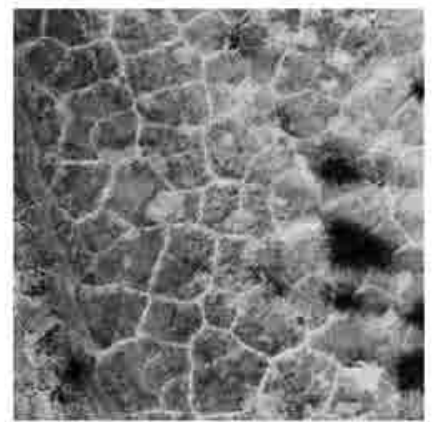

R1001796

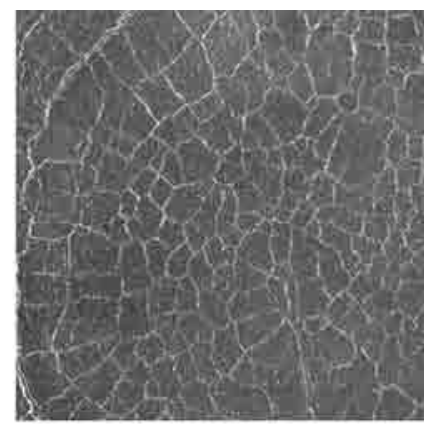

M1900047



S0701948

Fig. 2 - Examples of Martian polygonal networks (the side of each image is approximately $1 \mathrm{~km}$ ).

Fig. 2 - Exemplos de redes poligonais marcianas.

\section{METHODOLOGY FOR THE AUTOMATED DETECTION OF POLYGONS}

The development of the automated procedure to identify polygonal patterns is a work in progress (Pina et al., 2006). Though the current focus of this work is on the surface of Mars, other targets can be considered - the aim is to create a tool that can be applied to any kind of polygonal pattern, whatever the material, the scale, or the location. The methodology, which is based on mathematical morphology operators, comprises a number of steps, in order to tackle the issues raised by the type of images with which we may be confronted. In this paper, we exemplify the current state of the methodology through a series of images (fig. 3), whose explanation is given below. The example refers to a polygonal terrain that can be seen on MOC image R12-009900, centred on the coordinates $326.67 \mathrm{~W}$ and $54.99 \mathrm{~N}$, and with a spatial resolution of 3.32 meters per pixel. 




Fig. 3 - Sequence for automated detection (the side of the image is approximately $1 \mathrm{~km}$ ): (a) Initial image and delimitation of region of interest (small square on the top); (b) Noise filtering and polygon edge enhancement (morphological operators); (c) Delineation of homogeneous regions (segmentation by watershed); (d) Computation of the importance of each edge (dynamics); (e) Filtering the edges with lower dynamics (final result superimposed to initial image).

Fig. 3 - Sequência de detecção automática: (a) Imagem inicial e delimitação de região de interesse; (b) Filtragem de ruído e realce das arestas dos polígonos (operadores morfológicos);

(c) Delineação de regiões homogéneas (segmentação por watershed); (d) Cálculo da importância de cada aresta (dinâmica); (e) Filtragem das arestas com dinâmica baixa (resultado final sobreposto à imagem inicial).

The first phase can be called pre-processing. The original images, such as the one presented in figure $3 \mathrm{a}$, present some typical challenges, namely poor local definition of polygon edges, and lines that fail to reach other lines in order to close a polygon. During this phase, the image is made simpler: noise is eliminated and polygon contours are enhanced; if the gaps are small, dangling lines are artificially prolonged, and become "true" polygon edges. This is achieved through the sequential application of morphological filters (fig. 3b). The optimization of this sequence is a challenging task, and the current sequence will very likely be altered in future versions of the methodology. In the following phase, polygons are identified with the use of the watershed transform. This procedure is akin to the flooding of a topographical surface that begins at the lowest points (minima) of each closed basin. Whenever the waters of two adjacent basins 
would start to merge, there is a separation line - in this case, these lines should correspond to the edges of polygons. However, due to the unevenness that is a characteristic of natural surfaces, there is a tendency for the images to be oversegmented, that is, there are far more polygons in this image than in the original (fig. 3c). It is evident that not all of them should be allowed to remain in the image, and some kind of criterion must be employed to achieve this.

To answer this problem, an approach presented in response to another problem is applied (Najman and Schmitt, 1996). It consists in the evaluation of the dynamics of the contours, using a simple measure of the grey-level difference between a peak and its surrounding minima. In this case, and after some image processing, the peak is the saddle-point, the lowest point in the line that separates two adjacent basins (the point where the waters would start to merge). Thus, the dynamics of each line (polygon edge) is defined as the minor of the two differences between the gray-level of a saddle-point and the minima of the two adjacent basins. As a result, we obtain an image where the different relevance of the contours determined by the watershed operator is readily apparent, since they now have different grey levels - the most important are lighter in tone though in fig. $3 \mathrm{~d}$ they appear darker, since the image has been inverted for easier visualization. To eliminate the less important lines and, thus, to end with an image that is closer to the physical reality as it was captured in the original image, a threshold is employed, producing a much cleaner image (fig. 3e). Again, this step is crucial, since different values of this threshold can produce very diverse images; its choice is another point still under analysis.

So far, we have tested the methodology on a small number of images that show polygonal terrains on the surface of Mars. These were selected from images presented in works by other authors, and though they show clear differences in size, shape, and topology, they were used solely with the aim of detecting the polygons. In order to obtain a quantified evaluation of the results achieved by the methodology, we measured the length (number of pixels) of all contours automatically determined, and compared them with ground-truth images, in which the contours were manually identified. The numbers point to a very high level of concordance between human and automated detection of polygon edges, ranging between 80 and $99 \%$ of correct (pixel) detections, with very low levels of false positives. However, these are very preliminary results, and they show a strong influence of factors such as the characteristics of the original images. The current effort of selection of images and application of an improved methodology should lead to results much more statistically significant.

\section{CHARACTERIZATION OF POLYGONAL NETWORKS}

As mentioned before, the identification of polygons is only the first step to achieve our objectives. When the network has been detected, a number of parameters of the polygons that constitute it can be easily determined, and these can 
later be analysed. This analysis can be done for each of the parameters, but the relations between them will also be probed, taking into account that both geometric - area, orientation, shape, to name a few - and topological characteristics can be extracted. The weighing of these parameters against other factors, such as the geologic situation (namely the type of terrain and the presence of impact or tectonic structures) and the topographic location (low or high terrain) in which the polygonal patterns occur, will undoubtedly constitute a helping tool for their interpretation.

In figure 4, we show an example of a topological parameter determined for the network detected in the example of figure 3 . The mean number of neighbours for the 354 polygons constituting this network is 5.6. This can be compared with other networks on Mars and on the Earth, and even with those that occur in natural and artificial materials. The global values can be appreciated in the histogram (fig. 4 left), or seen superposed on the network itself (fig. 4 right). The distribution of values of yet another parameter, the area of the polygons, is presented in figure 5. This is a parameter that has a much more local significance, but it serves as an example of the set of geometric characteristics that we will collect, a list that is still under construction.
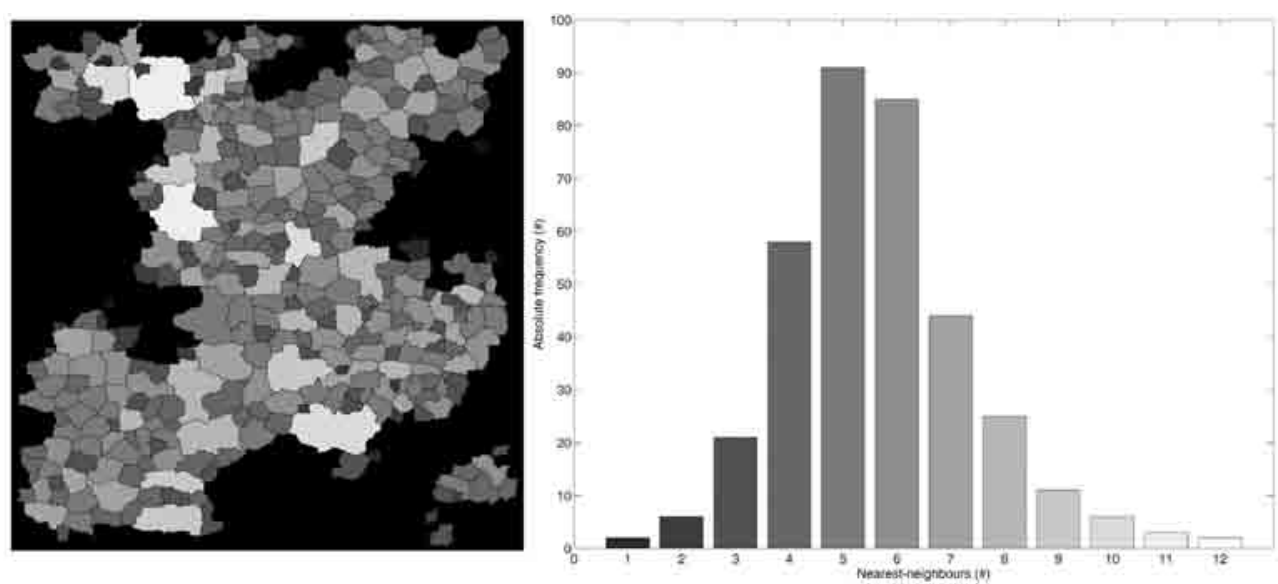

Fig. 4 - Topological characterization of the network mapped in figure 3. Computation of the number of neighbours of each polygon (left) and respective histogram (right).

Fig. 4 - Caracterização topológica da rede. Cálculo do número de vizinhos de cada polígono e respectivo histograma. 


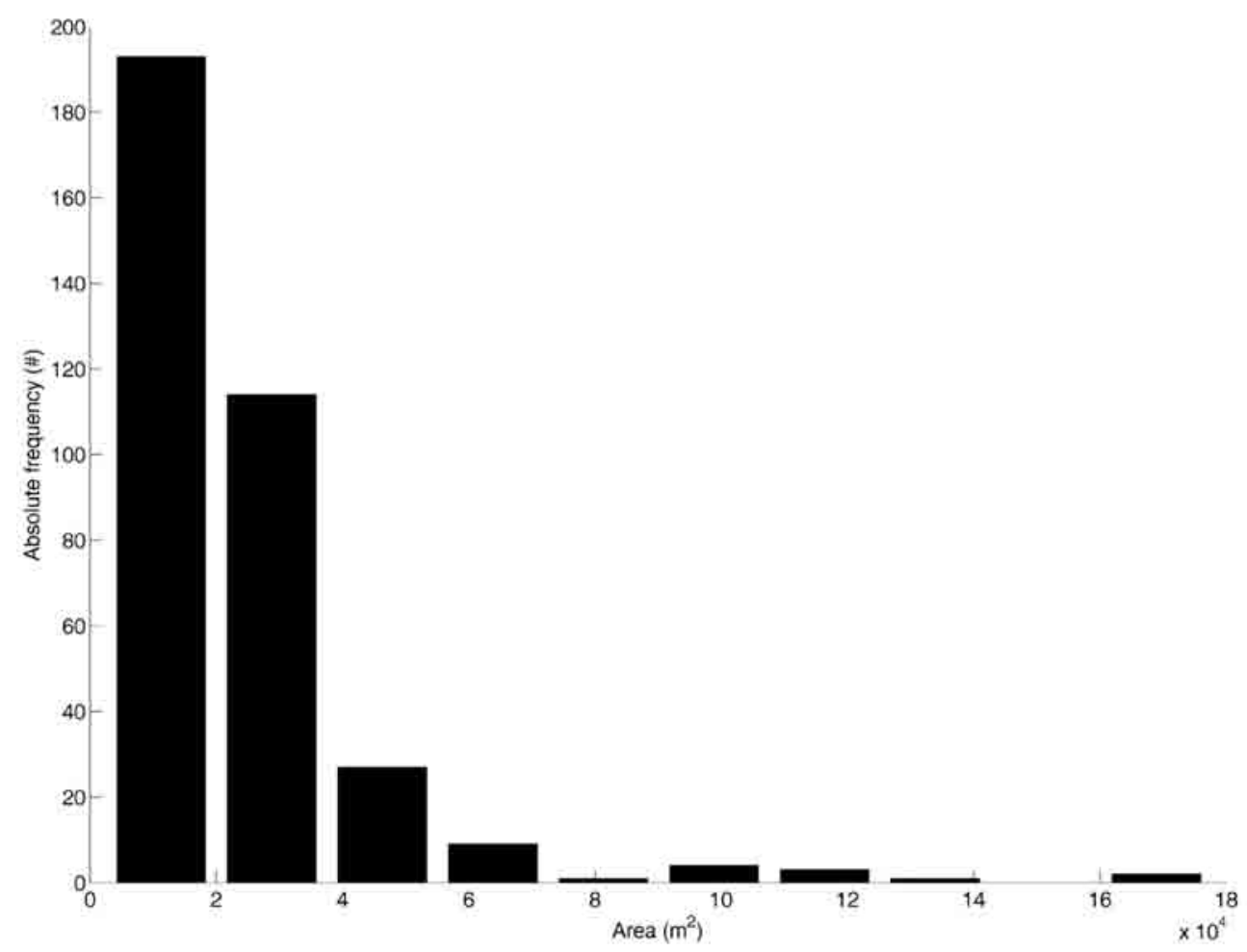

Fig. 5 - Size histogram of polygons in the network.

Fig. 5 - Histograma de tamanhos dos polígonos da rede.

\section{CONCLUSIONS}

The presence of polygonal terrains on the surface of Mars can be taken as an indicator of the existence of freeze-thaw processes in certain regions of the planet. This, in turn, can lead to the identification of areas of potential interest in the search for liquid water and signs of life, matters that assume high priority in the current effort to explore the planet.

The effort to develop an automated procedure for the identification and characterization of polygonal networks in images of the surface of the planet can lead to the acquisition of significant volumes of data on this type of feature. Their geometrical and topological parameters can then be related to other factors, such as topography and geological setting, in order to achieve an in-depth understanding of the conditions of their formation and evolution. The comparison with Earth analogs will also be a factor in this analysis; thus, we plan to collect data on terrestrial examples of diverse types of polygonal patterns. 


\section{ACKNOWLEDGMENTS}

This work was developed in the frame of project TERPOLI (PTDC/CTE-SPA/65092/2006), funded by Fundação para a Ciência e a Tecnologia (Portugal).

\section{REFERENCES}

Hiesinger H, Head J (2000) Characteristics and origin of polygonal terrain in southern Utopia Planitia, Mars: results from Mars Orbiter Laser Altimeter and Mars Orbiter Camera data. Jour. Geophys. Res., 105(E5): 11999-12022.

Kossacki K, Markiewicz W (2002) Martian seasonal $\mathrm{CO}_{2}$ ice in polygonal troughs in the southern polar region: role of the distribution of subsurface $\mathrm{H}_{2} \mathrm{O}$ ice. Icarus, 160(1): 73-85.

Kuzmin R (2005) Ground ice in the Martian regolith. In Tokano T (ed.) Water on Mars and Life. Springer, Berlin Heidelberg: 155-189.

Kuzmin R, Zabalueva E (2003) Polygonal terrains on Mars: preliminary results of global mapping of their spatial distribution. Abs., Lunar and Planetary Sci. Conf. XXXIV, 1912.

Langsdorf E, Britt D (2005) Classification and distribution of patterned ground in the southern hemisphere of Mars. Abs., Lunar and Planetary Sci. Conf. XXXVI, 2140.

Mangold N (2005) High latitude patterned grounds on Mars: classification, distribution and climatic control. Icarus, 174(2): 336-359.

Mangold N (2003) Distribution and climatic control of small scale polygons on Mars. Abs., $3^{\text {rd }}$ Int. Conf. Mars Polar Sci. Expl., 8044.

Mangold, N, Maurice S, Feldman W, Costard F, Forget F (2004) Spatial relationships between patterned ground and ground ice detected by the Neutron Spectrometer on Mars. Jour. Geophys. Res., 109(E08001), doi:10.1029/2004JE002235.

Najman L, Schmitt M (1996) Geodesic saliency of watershed contours and hierarchical segmentation. IEEE Trans. Patt. Anal. Mach. Intel., 18(12): 1163-1173.

Pina P, Saraiva J, Bandeira L, Barata T (2006) Identification of Martian polygonal patterns using the dynamics of watershed contours. In Campilho A, Kamel M (eds.) ICIAR2006. Springer-Verlag, Berlin Heidelberg: 691-699.

Seibert N, Kargel J (2001) Small-scale Martian polygonal terrain: implications for liquid surface water. Geophys. Res. Lett., 28(5): 899-902.

Van Gasselt, S, Reiss, D, Thorpe, A, Neukum, G (2005) Seasonal variations of polygonal thermal contraction crack patterns in a south polar trough, Mars. Jour. Geophys. Res., 110(E08002), doi:10.1029/2004JE002385.

Yoshikawa K (2000) Contraction cracking and ice wedge polygons in Mars. Abs., $2^{\text {nd }}$ Int. Conf. Mars Polar Sci. Expl., 4045. 